\title{
Impact of pre-transplant infection management on the outcome of living-donor liver transplantation in Egypt
}

This article was published in the following Dove Press journal:

Infection and Drug Resistance

\author{
Ahmed Mohamed Saleh' \\ Essam Ali Hassan' \\ Ahmed Ali Gomaa' \\ Tamer Mahmoud El Baz ${ }^{2}$ \\ Mohamed El-Abgeegy ${ }^{3}$ \\ Mohamed Ismail Seleem ${ }^{3}$ \\ Yousry Esam-Eldin \\ Abo-amer ${ }^{4}$ \\ Heba Fadl Elsergany ${ }^{3}$ \\ Eman Ibrahim El- \\ Desoki Mahmoud ${ }^{3}$ \\ Sherief Abd-Elsalam (iD ${ }^{5}$ \\ 'Tropical Medicine Department, Fayoum \\ University, Al Fayyum, Egypt; ${ }^{2}$ Endemic \\ Medicine Department, Cairo University, \\ Giza, Egypt; ${ }^{3}$ Liver Transplantation Team, \\ National Hepatology and Tropical \\ Medicine Research Institute, Cairo, Egypt; \\ ${ }^{4}$ Hepatology, Gastroenterology, and \\ Infectious Diseases Department, Mahala \\ Hepatology Teaching Hospital, Gharbia, \\ Egypt; ${ }^{5}$ Tropical Medicine Department, \\ Tanta University, Tanta, Egypt
}

Correspondence: Sherief Abd-Elsalam Tropical Medicine Department, Tanta

University, Tanta 35127, Egypt

Tel +201095159522

Email sherif.abdelbaky@med.tanta.edu.eg
Background and aim: Liver transplantation (LT) has emerged as an established therapeutic option for patients with chronic liver disease. Patients with end-stage liver disease are at high risk of infection with multidrug-resistant organisms, which may affect the outcome of LT. The aim of this study was to evaluate the impact of pre-transplant infection on the outcome of living-donor LT.

Methods: Prospective follow-up was done for 50 patients with chronic liver disease who had had LT performed from September 2013 to December 2017. We divided patients into group 1 (patients who had had infection within 3 months before transplantation with adequate treatment $[n=20]$ ), and group 2 (patients without infection $[n=30]$ ). Both groups were followed for 4 months post-operatively.

Results: Patients with high Modelfor End-Stage Liver Disease scores were more susceptible to infection pre- and post-operatively, and chest infection was the most common infection pre-transplant. There were no significant statistical differences regarding hospital and ICU stay and post-operative course between the groups, but the mortality rate was higher in group $1(40 \%)$ than in group $2(23.3 \%)$, and the causes of mortality in the group 1 were mainly due to medical causes (infections and sepsis, $75 \%$ ) versus $28.6 \%$ in group 2.

Conclusion: Liver-cell failure and concomitant infection 3 months before LT with adequate treatment had no significant statistical differences regarding hospital, ICU stay, or medical complications, but post-operative infection and mortality rate were more frequent in group 1 and the causes of mortality were mainly medical.

Keywords: hepatitis C virus, cirrhosis, steatosis, chronic liver disease, liver transplantation, outcome

\section{Introduction}

Liver transplantation (LT) is considered as an established therapeutic option for patients with acute and chronic liver failure and hepatocellular carcinoma. ${ }^{1}$ It evolved as a highly effective approach to treat many end-stage liver disease (ESLD) cases that had had no treatment before LT. ${ }^{2}$ Patients with liver cirrhosis are more susceptible to infections, due to alterations in gut microbiota, intestinal barrier dysfunction, genetic predisposition, and immunodysfunction. ${ }^{3}$ Being immunocompromised, they are predisposed to develop bacterial infections and sepsis, due to endothelial alterations, leukocyte dysfunction, bacterial translocation, and iatrogenic factors. ${ }^{4}$ Patients with severe ESLD and a high Model for End-Stage Liver Disease (MELD) score are at increased risk of infections in the period before 
and after LT. ${ }^{5}$ Infection could be with multidrug-resistant microorganisms, which can have an adverse impact on outcomes after LT. ${ }^{6}$ Also, acute-on-chronic liver failure may develop as sequela of a superimposed bacterial infection or sepsis. ${ }^{7}$ Egypt has an increasing number of patients with chronic LDs and LDs, due to the high prevalence of hepatitis $\mathrm{C}$ virus among the population, with an increasing need for LT. $^{8-14}$ In our study, we aimed to assess the impact of the presence of pre-transplant infections and treatment on the outcome of living-donor LT (LDLT).

\section{Methods}

This study was based on a prospective follow-up that was performed for 50 patients with chronic liver-cell failure who had had LT performed between September 2013 and December 2017 at a major tertiary-care hospital. The study was conducted in accordance with the Declaration of Helsinki. Patients were categorized to two groups: group 1, which comprised patients who had had infection within 3 months before LT with adequate treatment, and group 2, which comprised only patients who did not show any evidence of infection before transplantation. A pre-transplant infection was any infection that occurred within 3 months prior to LT, and was diagnosed by clinical, laboratory (eg, blood, ascites, sputum, stool, urine, and swabs), and/or imaging (eg, chest X-ray, ultrasonography, and computed tomography) findings. The commonest pre-transplant infections were chest infections, spontaneous bacterial peritonitis (SBP), urinary tract infections (UTIs), nasal infections, bacteremia, skin and soft-tissue infections, meningitis, and gastroenteritis.

Patients who had one of high or suboptimal temperature, tachycardia (heart rate $>100$ beats/minute), tachypnea (respiratory rate $>20$ breaths/minute), leukocytosis (white blood cells $>11,000 / \mathrm{mm}^{3}$ ) or leukopenia (white blood cells $<4,000 / \mathrm{mm}^{3}$ ) had pan-cultures and sensitivity (urine, stool, ascites, nasal swab, blood, sputum) performed. Chest infection was considered by the presence of progressive opacity on chest X-ray with fever, leukocytosis, purulent sputum, newly developed or worsening cough, tachypnea, tachycardia, crepitations detected at auscultation, and/or arterial oxygen desaturation. UTI was defined as the presence of dysuria, frequency and/or urgency, and pyuria. SBP was defined as the presence of ascetic polymorphonuclear neutrophilic count $>250$ cells $/ \mathrm{mm}^{3}$, regardless of culture results. Skin and soft-tissue infections, including cellulitis and necrotizing fasciitis, were defined as erythema and hotness or pus collection in the affected skin. Nasal infection was defined as hyperemic mucosa of the nostril with positive swab culture, including fungal and bacterial infections. Bacteremia was defined as positive blood culture with or without primary source of infection.

All patients with diagnosed bacterial or fungal infections started antibiotic or antifungal treatment that was then adjusted based on culture and sensitivity results. A pre-transplant bacterial infection was considered adequately treated and the patient regarded as a candidate for LT when manifestations of infection had disappeared, with normalization or improvement of laboratory and/or imaging findings that had previously indicated bacterial infection, as well as achieving negative culture and sensitivity tests at least 2 weeks before operation.

Most patients were admitted at two days pre-transplantation. Postoperatively, they were admitted to the ICU for 5 days till stabilization, transferred to the ward for 1-2 weeks, then discharged for outpatient follow-up. Follow up was performed weekly for the first 3 months to detect any complications, such as infections, renal impairment, immunosuppressant side effects, graft dysfunction, biliary stricture, and neurological abnormalities. Follow-up of patients include history-taking, general examination, and laboratory investigations, including complete blood count, complete liver profile, renal function, and trough levels of immunosuppressants. As for prophylaxis for postoperative bacterial and fungal infections, a combination of imipenem, metronidazole, trimethoprim-sulfamethoxazole and fluconazole was started immediately before operation and continued for 1 week postoperatively.

The immunosuppressive regimen consisted of longterm therapy with tacrolimus (Tac; the dose was modified according to the patient's trough serum level) and steroids that were gradually withdrawn and ended by the end of the third postoperative month. Tac was replaced by cyclosporin A in patients with adverse effects from Tac. Patients were followed for 4 months post-operatively to compare outcomes between the two groups. We compared patients according to their hospital and ICU stays, post-operative complications, including both medical (infection, sepsis, renal impairment, DIC, chest complications, cardiac complications, neurological complications), and surgical complications (hemorrhage, biliary complications, intraabdominal collections, excisional hernia), percentage of mortalites, and causes of death. 
Data were collected, coded, translated to English to facilitate data manipulation, double-entered into Microsoft Access, and analysis performed using SPSS 18 with Windows 7. Simple descriptive analysis is in the form of numbers and percentages for qualitative data, arithmetic means as central tendency measurement, SD as measure of dispersion for quantitative parametric data, and inferential statistical tests. For quantitative parametric data, we used paired $t$-tests in comparing two dependent quantitative data. As for qualitative data, $\chi^{2}$ was used to compare two or more variables. Bivariate correlations were used to test associations between variables. $P \leq 0.05$ was considered the cutoff value for significance.

\section{Results}

Fifty patients received adult-to-adult LDLT during the study (42 men and eight women). Their median age was 47.1 (18-65) years. Patients were categorized as those with pre-transplant infection (group $1, \mathrm{n}=20$ ) and those without pre-transplant infection (group 2, $\mathrm{n}=30$ ). Demographic, laboratory and clinical features were comparable between the groups Chronic LD due to hepatitis $\mathrm{C}$ virus was the most commonly encountered indication for transplantation (Table 1). All cases were right-lobe grafts. A total of 29 pre-transplant-infection episodes were found in the 20 LDLT recipients. Among these patients, nine $(45 \%)$ experienced one episode of pre-transplant infection, while eleven patients experienced two or more episodest. Pre-transplant-infection entities were chest infection $(n=10)$, nasal mucosal infection $(\mathrm{n}=8)$, UTI $(\mathrm{n}=6)$, SBP $(\mathrm{n}=4)$, and gastroenteritis $(\mathrm{n}=1)$. All patients with pre-transplant infection received effective antibiotic therapy and were considered eligible for LT from 2 weeks after cure from infection (Table 2).

Concerning outcomes after LT, no significant difference was found in length of hospital or ICU stay, and both groups had comparable post-operative courses regarding medical complications (35\% for group 1 versus $30 \%$ for group 2$)$. These included rejection and posttransplant-infection rates. Higher MELD score in group 1 than group 2 was the only causative factor potentially contributing to the development of postoperative complications and infections. There was one case of poor graft function related to "small-for-size syndrome". There were severe biliary complications in ten cases: four developed biliary leak and anastomotic stricture, four biliary stricture and biliary leak, three biliary leak, and
Table I Demographic, clinical, and laboratory features of the studied group

\begin{tabular}{|c|c|c|c|}
\hline & Mean & Normal range & SD \\
\hline Age & \multicolumn{2}{|l|}{47.1} & \pm 9.7 \\
\hline MELD score & 16.2 & & \pm 3.9 \\
\hline INR & 1.5 & $(1-1.2)$ & \pm 0.37 \\
\hline TLC (cells $/ \mathrm{mm}^{3}$ ) & $4.8 \times 10^{3}$ & $(4-I I)$ & \pm 2.12 \\
\hline CRP (mg/L) & 10.25 & $(0-6)$ & \pm 11.38 \\
\hline Albumin (g/dL) & 2.66 & $(3.5-5.5)$ & \pm 0.66 \\
\hline Creatinine $(\mathrm{mg} / \mathrm{dL})$ & 0.93 & $(0.6-1.2)$ & \pm 0.35 \\
\hline Bilirubin (mg/dL) & 3.7 & $(0.3-1)$ & \pm 2.8 \\
\hline \multirow[t]{2}{*}{$\operatorname{ESR}(\mathrm{mm} / \mathrm{h})$} & 38.8 & $(0-15)$ & \pm 25.8 \\
\hline & \multicolumn{2}{|l|}{$\mathbf{n}$} & $\%$ \\
\hline \multicolumn{4}{|l|}{ Sex } \\
\hline Male & \multicolumn{2}{|l|}{42} & 84 \\
\hline Female & \multicolumn{2}{|l|}{8} & 16 \\
\hline \multicolumn{4}{|l|}{ Child-Pugh score } \\
\hline A & \multicolumn{2}{|l|}{6} & 12 \\
\hline B & \multicolumn{2}{|l|}{14} & 28 \\
\hline C & \multicolumn{2}{|l|}{30} & 60 \\
\hline \multicolumn{4}{|l|}{ Indication for LT } \\
\hline HCV-CLD & \multicolumn{2}{|l|}{40} & 80 \\
\hline HBV-CLD & \multicolumn{2}{|l|}{2} & 4 \\
\hline AlH-CLD & \multicolumn{2}{|l|}{4} & 8 \\
\hline Cryptogenic CLD & \multicolumn{2}{|l|}{4} & 8 \\
\hline Patients who had $\mathrm{HCC}$ & \multicolumn{2}{|l|}{13} & 26 \\
\hline
\end{tabular}

Abbreviations: MELD, Model for End-Stage Liver Disease; INR, international normalized ratio; TLC, total lymphocyte count; ESR, erythrocyte-sedimentation rate; LT, liver transplantation; HCV, hepatitis C virus; CLD, chronic liver disease; $\mathrm{AlH}$, autoimmune hepatitis; $\mathrm{HCC}$, hepatocellular carcinoma.

one epigastric biloma. The mortality rate was higher in group 1 (eight patients, 40\%) than in group 2 (seven patients, 23.3\%), and causes of mortality in group 1 were mainly medical (mainly infections and sepsis) in six $(75 \%)$ versus two patients $(28.6 \%)$ in group 2 $(P=0.03)$. However, these results did not show statistically significant differences (Table 3). Finally, eleven post-transplant-infection episodes occurred in eight patients (six [30\%] in group 1 and two [6.6\%] in group 2, $P=0.027)$. These episodes and pathogens are detailed in Table 4. Intra-abdominal infections were the most frequently encountered post-transplant infection, of which Enterococcusspp. were the leading pathogens.

\section{Discussion}

We observed 29 pre-transplant-infection episodes that developed in 20 patients $(40 \%)$ of the total patients studied. Also, 
Table 2 Descriptive analysis of episodes of pre-transplant infection $(n=29)$ found in 20 living-donor liver-transplant recipients

\begin{tabular}{|l|l|l|}
\hline & $\mathbf{n}$ & $\%$ \\
\hline Infection & & \\
Present & 20 & 40 \\
Absent & 30 & 60 \\
\hline Type of infections & & \\
Chest & 3 & 15 \\
UTI & 3 & 15 \\
Nasal & 3 & 15 \\
Chest and nasal & 3 & 15 \\
Chest and UTI & 2 & 10 \\
SBP & 2 & 10 \\
Chest, nasal, and SBP & 1 & 5 \\
Chest and SBP & 1 & 5 \\
UTI and nasal & 1 & 5 \\
Gastroenteritis & 1 & 5 \\
\hline Frequency of infection by site & & \\
Chest & 10 & 50 \\
Nasal & 8 & 40 \\
UTI & 6 & 30 \\
SBP & 4 & 20 \\
Gastroenteritis & 1 & 5 \\
\hline Time of last infection prior to operation & & \\
Less than I month & 2 & 10 \\
I-2 months & 4 & 70 \\
2-3 months & 20 \\
\hline
\end{tabular}

Abbreviations: UTI, urinary tract infection; SBP, spontaneous bacterial peritonitis.

we observed that patients with higher MELD scores (17.2) were those who mostly developed infection in the pre-transplantation period. This was similarly to Sun et al ${ }^{15}$ and Reddy et $\mathrm{al},{ }^{5}$ who mentioned that high MELD score and severe ESLD were associated with increasing susceptibility to infections before and after LT.

Chest infection was the most common pre-transplant infection, followed by nasal infection, UTI, SBP, and lastly gastroenteritis. According to Fernandez et al, the most common infections in cirrhotic patients are SBP $(25 \%)$, UTI (20\%), pneumonia (15\%), bacteremia following a therapeutic procedure, cellulitis, and spontaneous bacteremia. ${ }^{16}$ In 2014, Thévenot et al reported that chest infection was the most common infection in cirrhotic patients, followed by UTI. ${ }^{17}$ However, these results disagreed with Garcia-Tsao, who reported that SBP was the most common infection to occur in pre-transplant patients. ${ }^{18}$ Also, they disagreed with Lin et al, who found that UTI was the most common infection to occur in their study of 54 pre-transplant patients. ${ }^{19}$ We found that SBP prevalence in our ascitic patients was $18 \%$. This coincided with Garcia-Tsao, who noted that SBP in hospitalized cirrhotic patients with ascites was $10 \%-30 \%$. Postoperatively, we found that patients in group 1 were more susceptible to infection (30\%) than group $2(6.6 \%){ }^{18}$ The most common types of infection were intra-abdominal infection, chest infection, bloodstream infection, nasal infection, necrotizing fasciitis, and maxillary sinusitis.

Patients with liver-cell failure and concomitant infections within 3 months before LT and who received adequate treatment showed no significant statistical differences regarding hospital or ICU stay and had a comparable post-operative course regarding medical complications (35\% for group 1 versus $30 \%$ for group 2). Patients were followed for 4 months post-operatively to compare outcomes between the groups. Patients with ESLD are predisposed to infection with multidrug-resistant microorganisms that can have an adverse impact on outcome after LT. ${ }^{6}$ Lin et al ${ }^{19}$ suggested that adequately treated pre-transplant infections do not significantly affect clinical outcomes, including post-transplant fatality in recipients in adult-to-adult LDLT, and there was no significant difference found in length of post-transplant ICU stay, 1-year survival, graft rejection, or post-transplantinfection rates between the groups.

Our recorded mortality rates were higher in group 1 (eight patients, $40 \%$ ) than group 2 (seven patients, 23.3\%), and the causes of mortality in group 1 were mainly medical in six patients $(75 \%)$ versus two $(28.6 \%)$ in group 2, but these results were of no statistical significance. Regarding mortality due to sepsis, this was more frequent in group $1(62.5 \%)$ than group $2(42.8 \%)$. Bertuzzo et $\mathrm{al}^{20}$ reported that bacterial infection 1 month before LT was related to a higher rate of infection after transplantation, but did not lead to a worse outcome. Also, Hara et $\mathrm{al}^{21}$ reported that 20 patients who underwent LDLT with an infection 1 month before transplant had a lower 1-year post-transplant survival rate than patients without infection (65\% versus $86 \%$, respectively).

The main limitation of this study was the small sample and limited follow-up. Studies on larger populations with more prolonged follow-up are needed to support or refute the results of this study.

In conclusion, liver-cell failure and concomitant infection 3 months before LT with adequate treatment showed no significant statistical differences regarding hospital/ICU stay or medical complications. However; postoperative 
Table 3 Post-operative course of both groups

\begin{tabular}{|c|c|c|c|c|c|}
\hline & \multicolumn{2}{|c|}{ Group I $(n=20)$} & \multicolumn{2}{|c|}{ Group $2(n=30)$} & \multirow[t]{2}{*}{$P$-value } \\
\hline & $\mathbf{n}$ & $\%$ & $\mathbf{n}$ & $\%$ & \\
\hline $\begin{array}{l}\text { Hospital stay (days) } \\
\text { ICU stay (days) }\end{array}$ & \multicolumn{2}{|c|}{$\begin{array}{l}|9.6 \pm 6 .| \\
8.2 \pm 5.6\end{array}$} & \multicolumn{2}{|c|}{$\begin{array}{l}23 \pm 10.1 \\
7.1 \pm 3.3\end{array}$} & $\begin{array}{l}0.185 \\
0.403\end{array}$ \\
\hline $\begin{array}{l}\text { Complications } \\
\text { - Yes } \\
\text { - No }\end{array}$ & $\begin{array}{l}11 \\
9\end{array}$ & $\begin{array}{l}55.0 \\
45.0\end{array}$ & $\begin{array}{l}19 \\
11\end{array}$ & $\begin{array}{l}63.3 \\
36.7\end{array}$ & 0.349 \\
\hline $\begin{array}{l}\text { Surgical complications } \\
\text { - Yes } \\
\text { - No }\end{array}$ & $\begin{array}{l}3 \\
17\end{array}$ & $\begin{array}{l}15.0 \\
85.0\end{array}$ & $\begin{array}{l}9 \\
23\end{array}$ & $\begin{array}{l}33.3 \\
66.7\end{array}$ & 0.720 \\
\hline $\begin{array}{l}\text { Medical complications } \\
\text { - Yes } \\
\text { - No }\end{array}$ & $\begin{array}{l}8 \\
13\end{array}$ & $\begin{array}{l}35 \\
65\end{array}$ & $\begin{array}{l}10 \\
20\end{array}$ & $\begin{array}{l}30 \\
60\end{array}$ & 0.902 \\
\hline Infection & 6 & 30 & 2 & 6.6 & 0.027 \\
\hline Mortality & 8 & 40 & 7 & 23.3 & 0.208 \\
\hline $\begin{array}{l}\text { Mortality causes } \\
\text { - Medical } \\
\text { - Surgical }\end{array}$ & $\begin{array}{l}6 \\
2\end{array}$ & $\begin{array}{l}75 \\
25\end{array}$ & $\begin{array}{l}2 \\
5\end{array}$ & $\begin{array}{l}28.6 \\
71.4\end{array}$ & 0.132 \\
\hline
\end{tabular}

Notes: Group I: patients with treated infections. Group 2: patients without infection.

Table 4 Episodes of post-transplant infection $(n=I I)$ found in eight living-donor liver-transplant recipients

\begin{tabular}{|c|c|c|}
\hline Infection category & Organisms & Episodes \\
\hline Chest infection & $\begin{array}{l}\text { - Escherichia coli and streptococci } \\
\text { - Acinetobacter and Klebsiella pneumoniae }\end{array}$ & $16.6 \%(2 / 12)$ \\
\hline Bloodstream infections & $\begin{array}{l}\text { - E. coli } \\
\text { - Enterococci }\end{array}$ & $16.6 \%(2 / 12)$ \\
\hline Intra-abdominal infections & $\begin{array}{l}\text { - Enterococci } \\
\text { - Staphylococcus aureus and Gram-negative bacilli, ESBL strain } \\
\text { - E. coli - enterococcus }\end{array}$ & $25 \%(3 / / 2)$ \\
\hline Nasal infection & - Streptococcus saprophyticus & $8.3 \%(I / I 2)$ \\
\hline Necrotizing fasciitis & - Streptococcus and Staphylococcus aureus & $8.3 \%(1 / / 2)$ \\
\hline Maxillary sinusitis & - Streptococcus aureus pneumonia & $8.3 \%(1 / 12)$ \\
\hline Wound infection & - E. coli & $8.3 \%(I / I 2)$ \\
\hline
\end{tabular}

infection and mortality rates were more frequent in this special category of patients.

\section{Ethics and consent}

Participants provided written informed consent, and the study was approved by the Tanta University Faculty of Medicine Research Ethical Committee.

\section{Disclosure}

The authors report no conflicts of interest in this work.

\section{References}

1. Graziadei I, Zoller H, Fickert P, et al. Indications for liver transplantation in adults. Wien Klin Wochenschr. 2016;128:679-690. doi:10.1007/ s00508-016-1046-1

2. Sagmeister M, Mullhaupt B, Kadry Z, Kullak-Ublick GA, Clavien PA, Renner EL. Cost-effectiveness of cadaveric and living-donor liver transplantation. Transplantation. 2002;73:616-622.

3. Jalan R, Gines P, Olson J, et al. Acute-on- chronic liver failure. $J$ Hepatol. 2012;57:1336-1348. doi:10.1016/j.jhep.2012.06.026

4. Acevedo J, Fernandez J. New determinants of prognosis in bacterial infections in cirrhosis. World J Gastroenterol. 2014;20:7252-7259. doi:10.3748/wjg.v20.i23.7252 
5. Reddy KR, O'Leary JG, Kamath PS, et al. High risk of delisting or death in liver transplant candidates following infections: results from the North American Consortium for the study of end-stage liver disease. Liver Transpl. 2015;21:881-888. doi:10.1002/1t.24139

6. Mah A, Wright A. Infectious considerations in the pre-transplant evaluation of cirrhotic patients awaiting orthotopic liver transplantation. Curr Infect Dis Rep. 2016;18:4. doi:10.1007/s11908-015-0514-5

7. Moreau R, Jalan R, Gines P, et al. Acute-on chronic liver failure is a distinct syndrome that develops in patients with acute decompensation of cirrhosis. Gastroenterology. 2013;144:1441426-1441437.

8. Ahmed OA, Kaisar HH, Hawash N, et al. Efficacy of sofosbuvir plus ribavirin with or without peginterferon-alfa in treatment of a cohort of Egyptian patients with hepatitis C virus infection. Infect Disord Drug Targets. 2017;17(2):95-100. doi:10.2174/1871526517666170417143216

9. Abd-Elsalam S, Sharaf-Eldin M, Soliman S, Elfert A, Badawi R, Ahmad YK. Efficacy and safety of sofosbuvir plus ribavirin for treatment of cirrhotic patients with genotype 4 hepatitis $C$ virus in real-life clinical practice. Arch Virol. 2018;163(1):51-66. doi:10.1007/s00705-017-3573-0

10. Ahmed OA, Kaisar HH, Badawi R, et al. Efficacy and safety of sofosbuvir-ledipasvir for treatment of a cohort of Egyptian patients with chronic hepatitis C genotype 4 infection. Infect Drug Resist. 2018;11:295-298. doi:10.2147/IDR.S153060

11. Ahmed OA, Elsebaey MA, Fouad MHA, et al. Outcomes and predictors of treatment response with sofosbuvir plus daclatasvir with or without ribavirin in Egyptian patients with genotype 4 hepatitis $\mathrm{C}$ virus infection. Infect Drug Resist. 2018;11:441-445. doi:10.2147/ IDR.S160593

12. Ahmed OA, Safwat E, Khalifa MO, et al. Sofosbuvir plus daclatasvir in treatment of chronic hepatitis $C$ genotype 4 infection in a Cohort of Egyptian Patients: an experiment the size of Egyptian village. Int $J$ Hepatol. 2018;2018:9616234. doi:10.1155/2018/9616234
13. Abd-Elsalam S, Badawi R, Elnawasany S, et al. Sofosbuvir, pegylated interferon and ribavirin in treatment of an Egyptian cohort with hepatitis C virus infection in real life clinical practice. Infect Disord Drug Targets. 2018. doi:10.2174/1871526518666180912121835

14. Sharaf-Eldin M, Bediwy AS, Kobtan A, et al. Pigtail catheter: a less invasive option for pleural drainage in Egyptian patients with recurrent hepatic hydrothorax. Gastroenterol Res Pract. 2016;2016:4013052. doi: $10.1155 / 2016 / 4013052$

15. Sun HY, Cacciarelli TV, Sing N. Impact of pretransplant infections on clinical outcomes of liver transplant recipients. Liver Transpl. 2010;16:222-228. doi:10.1002/lt.21982

16. Fernandez J, Navasa M, Gómez J, et al. Bacterial infections in cirrhosis: epidemiological changes with invasive procedures and norfloxacin prophylaxis. Hepatology. 2002;35(1):140-148. doi:10.1053/ jhep.2002.30082

17. Thévenot T, Bureau C, Oberti F, et al. Effect of albumin in cirrhotic patients with infection other than spontaneous bacterial peritonitis. A randomized trial. Journal of Hepatology. 2014;60:S29. doi:10.1016/j. jhep.2014.11.017

18. Garcia-Tsao G. Bacterial infections in cirrhosis. Can J Gastroenterol. 2004; 18:405-406. doi:10.1155/2004/769615

19. Lin KH, Liu JW, Chen CL, et al. Impacts of pretransplant infections on clinical outcomes of patients with acute-on-chronic liver failure who received living-donor liver transplantation. PLOS ONE. 2013;8 (9):e72893. doi:10.1371/journal.pone.0072893

20. Bertuzzo VR, Giannella M, Cucchetti A, et al. Impact of preoperative infection on outcome after liver transplantation. British_Journal_of_Surgery. 2017;104(2):e172-e181. doi:10.1002/ bjs. 10449

21. Hara T, Soyama A, Takatsuki M, et al. The impact of treated bacterial infections within one month before living donor liver transplantation in adults. Ann Transplant. 2014;19:674-679. doi:10.12659/AOT.892095
Infection and Drug Resistance

\section{Publish your work in this journal}

Infection and Drug Resistance is an international, peer-reviewed openaccess journal that focuses on the optimal treatment of infection (bacterial, fungal and viral) and the development and institution of preventive strategies to minimize the development and spread of resistance. The journal is specifically concerned with the epidemiology of antibiotic resistance and the mechanisms of resistance development and diffusion in both hospitals and the community. The manuscript management system is completely online and includes a very quick and fair peerreview system, which is all easy to use. Visit http://www.dovepress.com/ testimonials.php to read real quotes from published authors. 